\title{
GLIOSARCOMA
}

\section{Report of four cases with immunohistochemical findings}

\author{
Tiago Noguchi Machuca', Daniel Monte-Serrat Prevedello, \\ Leonora Zozula Blind Pope 3 , Salo Semelman Haratz', \\ João Cândido Araújo , Luiz Fernando Bleggi Torres ${ }^{5}$
}

\begin{abstract}
Gliosarcoma (GSa) is a rare primary central nervous system neoplasm (CNS) characterized by biphasic histological pattern with both glial and sarcomatous components. Our objective is to describe the clinical, morphological and immunohistochemical features of four cases of GSa and to discuss its pathogenetic mechanisms. The male:female ratio was 3:1. The mean age was 39 years, ranging from 19 to 48 . Headache was the commonest clinical symptom. All patients underwent craniotomy with microsurgery and total resection of the tumor. Diagnosis was suspected due to microscopic architecture and confirmed by detection of reticulin fibers through histochemical techniques. Immunohistochemical analysis was positive for p53 in both glial and sarcomatous cells in all four cases. EGFR was focally positive in glial cells in one case. Our findings support monoclonal origin of GSa involving the TP53 tumor-suppressor gene. However, alternative pathways cannot be ruled out.
\end{abstract}

KEY WORDS: brain neoplasms, gliosarcoma, immunohistochemistry.

\section{Gliossarcoma: relato de quatro casos com achados imuno-histoquímicos}

RESUMO - Gliossarcoma (GSa) é uma neoplasia primária rara do sistema nervoso central, caracterizada por padrão histológico bifásico incluindo componentes tanto glial como sarcomatoso. São discutidos os aspectos clínicos, morfológicos e imunohistoquímicos de quatro casos de GSa e seus mecanismos patogêneticos. A relação masculino/feminino foi 3:1. A média de idade foi 39 anos, variando de 19 a 48. Cefaléia foi a manifestação predominante. Todos os pacientes foram submetidos a craniotomia com microcirurgia e ressecção total do tumor. O diagnostico foi suspeitado devido à arquitetura microscópica e foi confirmada por presença de fibras de reticulina através de técnicas de histoquímica. A análise imuno-histoquímica foi positiva para p53 tanto em células gliais como em células sarcomatosas nos quatro casos. EGFR foi localmente positivo em células gliais em apenas um caso. Esses achados apoiam uma origem monoclonal do GSa relacionada com alteração no Tp53, gene supressor de tumor. No entanto, outras vias alternativas na gênese desses tumores não podem ser afastadas.

PALAVRAS-CHAVE: neoplasias cerebrais, gliossarcoma, imuno-histoquímica.

Gliosarcoma (GSa) is a rare primary neoplasm of the central nervous system (CNS) classified by the World Health Organization (WHO) as a variant of glioblastoma, therefore a grade IV tumor ${ }^{1}$. It is characterized by biphasic pattern displaying both glial and sarcomatous components. Feigin and Gross, who first described GSa, suggested that the cell of origin would arise from neoplastic transformation of blood vessels in a preexisting glioblastoma ${ }^{2}$. However, recent immunohistochemical and genetic studies failed to support this theory, suggesting a monoclonal origin for both histological components ${ }^{1}$.

GSa corresponds to less than $2 \%$ of all glioblastomas', with a peak of incidence from the fourth to the sixth decades of life, mean age 53 years. Male: female ratio is 1.8:1 and the clinical presentation, natural history and radiologic profile are similar to those of primary glioblastoma ${ }^{1,3}$.

We studied four cases of gliosarcoma aiming to

Department of Neurosurgery and Pathology, Hospital Nossa Senhora das Graças, Curitiba, Paraná, Brazil (HNSG); and Department of Pathology, Universidade Federal do Paraná, Curitiba, Paraná, Brazil (UFPR): ' ${ }^{1}$ Medical student, UFPR; ${ }^{2}$ Resident in Neurosurgery, HNSG; ${ }^{3}$ Resident in Pathology, Hospital de Clínicas, UFPR; ${ }^{4}$ Adjunct Professor of Neurosurgery, UFPR and Coordinator of the Program of Medical Residency of the Department of Neurosurgery, HNSG; ${ }^{5}$ Professor of Pathology, Universidade Federal do Paraná; Chairman of the Laboratory of Anatomical Pathology Service, HNSG. Tiago Noguchi Machuca is supported by a grant from UFPR/National Treasure. Salo Semelman Haratz is supported by a grant from PIBIC/CNPq.

Received 24 November 2003, received in final form 27 February 2004. Accepted 29 March 2004.

Dr. Luiz Fernando Bleggi Torres - Department of Pathology - Hospital de Clínicas, Universidade Federal do Paraná - Rua General Carneiro 181 - 80060-900 Curitiba PR - Brasil. E-mail: bleggi@hc.ufpr.br 
describe its clinical and pathological features. Immunohistochemical analyses were performed to confirm diagnosis, assess histogenetic origin and evaluate the proliferation index in all cases.

\section{METHOD}

The cases were selected from the files of the "CNS Tumor Bank", which is part of the section of Neuropathology of the Department of Pathology, Federal University of Parana, in Curitiba, from 1990 to 2002. This tumor bank collects around $95 \%$ of brain tumors diagnosed in the city of Curitiba, a 1.5 million inhabitants city in Southern region of Brazil. Clinical data were obtained by reviewing the medical records of all patients.

Histologic sections from all four cases were reviewed and original available paraffin-embedded blocks were recut and stained with hematoxylin/eosin and reticulin. The sarcomatous component was classified and both components were quantified. Mitotic figures per high power field were counted and type and extension of necrosis assessed.

Immunohistochemical study using the avidin-biotin method was performed with antibodies to GFAP, vimentin, CD34, p53, EGFR and Ki-67. Positive and negative controls were obtained for each antibody. GFAP and vimentin were classified as focal positivity, diffuse positivity and negative. CD34 and EGFR were classified as negative or positive. Ki-67 and p53 were considered positive only when nuclear staining was present and were graded as + when less than $1 \%$ of nuclei were stained; ++ when between $1 \%$ and $5 \%$ were stained, and +++ when more than $5 \%$ of stained nuclei were observed.

\section{RESULTS}

The CNS Tumor Bank of Curitiba has 3873 biopsy cases, with $92.4 \%$ of these corresponding to CNS primary tumors. From the CNS primary tumors, we obtained $5 \mathrm{GSa}(0.13 \%)$. Due to lack of appropriate material from one of the cases, we were able to histologically review and perform immunohistochemical analysis in only four cases.

\section{Clinical findings}

Case 1. A 43-years old male had experienced headaches over the 40 days before seeking medical assistance and a progressive loss of strength and sensation in the left lower limb. On admission he was confused, with left side hemiplegia. Both CT and MRI showed an irregular enhancing lesion in the right parietal and temporal lobes with a significant mass due to surrounding edema, causing a midline shift to the left. The patient was placed on corticosteroids and submitted to microsurgery thro- ugh a right temporo-parietal craniotomy. The tumor, which was grayish and hard, was macroscopically totally removed without significant blood loss. The patient improved the motor deficit mainly in the left upper limb and was discharged on the $5^{\text {th }}$ postoperative day. He died 3 months after the procedure.

Case 2. A 44-years old male presented with the clinical picture resembling uncinate fits one month before admission, which consisted in the anomalous perception of the smell of paints, followed by fainting spells and nonspecific headaches. He was taken to the hospital due to recent mental confusion, memory deficits and expressive aphasia, which were evident on clinical examination, besides right hemiparesis. Both CT and MRI showed an irregular infiltrating enhancing mass lesion in the left fronto-temporal lobes with slight surrounding edema (Figure 1). The patient was submitted to temporal lobectomy including the mesial structures. He received adjuvant radiotherapy during the following month. He persisted aphasic, but not confused during the next three months, without other clinical signs, when the symptoms recurred. He died 6 months after the surgical procedure.

Case 3. A 48-years old male had complained of pain in the left temporal area for 4 years, which he presumed was an earache. The patient was previously blind of the left eye and 2 months before admission, headaches worsened and he developed a left palpebral ptosis. He was initially seen by an ophthalmologist, who diagnosed glaucoma. Further work-up, including CT and MRI showed an irregular infiltrating enhancing mass lesion in the left temporo-parietal lobes with surrounding edema and compression of the left cerebral peduncle. On admission he was blind of the left eye with associated left palpebral ptosis. Left facial numbness, right hemiparesis and right hyperreflexia were also present. The patient was placed on corticosteroids and submitted to left temporo-parietal craniotomy. The tumor, which was grayish, soft and bloody, was macroscopically totally removed. The patient received radiotherapy during the following month and died 5 months after the surgical procedure.

Case 4. A 21-years old woman, who presented with headaches for 18 months, underwent surgery elsewhere six months before admission, when a right parieto-occipital tumor was removed, followed by radiotherapy. On admission she had a left hemiplegia and a left homonimous hemianopia. CT 
scan and MRI showed an irregular enhancing mass lesion in the right parieto-occipital lobes involving midline structures, invading right lateral ventricle and infiltrating corpus callosum. The patient was placed on corticosteroids and reoperated through the same approach. The tumor, which was macroscopically totally removed, was grayish, soft, and bloody. The lesion, interpreted initially as a malignant meningioma, had the diagnosis of gliosarcoma established trough immunohistochemical analysis. She died 4 months after the second procedure.

The main clinical findings are summarized in Table 1.

Histological and immunohistochemical findings

All four cases displayed sarcomatous and glial components. The glial component was remarkably similar to a glioblastoma, with nuclear pleomorphism, high mitotic index, marked vascular prolif- eration and foci of necrosis, either focal or geographical (Fig 2A).

The sarcomatous component consisted of groups of spindle cells arranged in a fashion that resembled fibrosarcoma in all cases (Fig 2A). In order to evaluate the mesenchymal component, histochemical study to reticulin fibers was performed and demonstrated a rich network of fibrils in all cases (Fig 2B).

The glial component comprised greater than $50 \%$ of the neoplasm in only one case. In the remaining three cases, the sarcomatous component comprised $70 \%, 80 \%$ and $90 \%$ of the sampled neoplasm, respectively. Mitotic figures per 5 highpower fields in the glial neoplasm ranged between 8 and 2 (mean 6.25). In the sarcomatous areas, the number of mitotic figures per 5 high-power fields ranged between 6 and 2 (mean 3).

Immunohistochemical findings are illustrated in Table 2, Figures $2 \mathrm{C}$ and 2D.

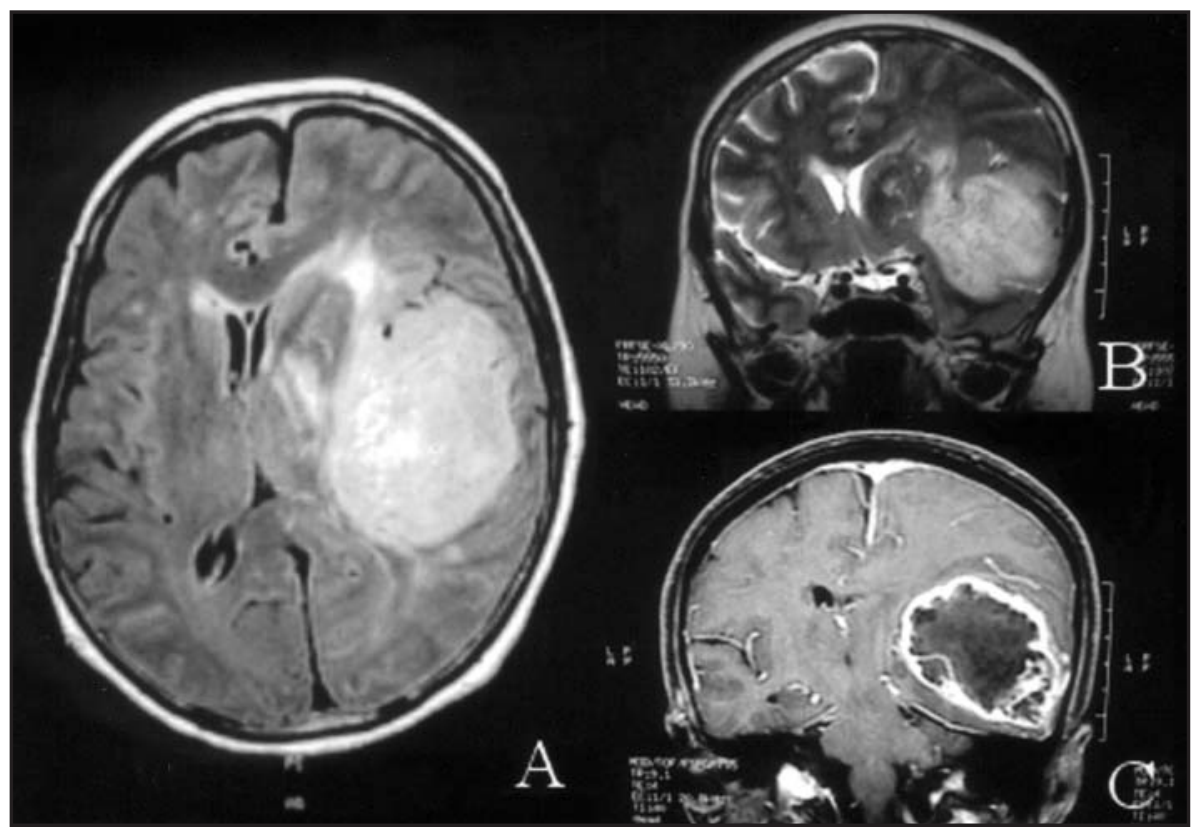

Fig 1. MR images of case 2 displaying a bulging lesion with marked peripheral edema and midline deviation localized on the fronto-parietal region ( $A$, axial view; $B$, coronal view). Peripheral enhancement of the lesion was observed after contrast medium injection (C).

Table 1. Clinical findings of gliosarcomas.

\begin{tabular}{lccccc}
\hline Case & Age & Sex & Presenting symptom & Site of lesion & Follow-up \\
\hline 1 & 43 & male & headache & R temporo-parietal & $\dagger$ in 3 months \\
2 & 44 & male & olfactory allucinations & L fronto-temporal & $\dagger$ in 6 months \\
3 & 48 & male & headache & L temporo-parietal & $\dagger$ in 5 months \\
4 & 21 & female & headache & R parieto-occipital & $\dagger$ in 4 months \\
\hline
\end{tabular}

$R$, right; $L$, left; + , death. 


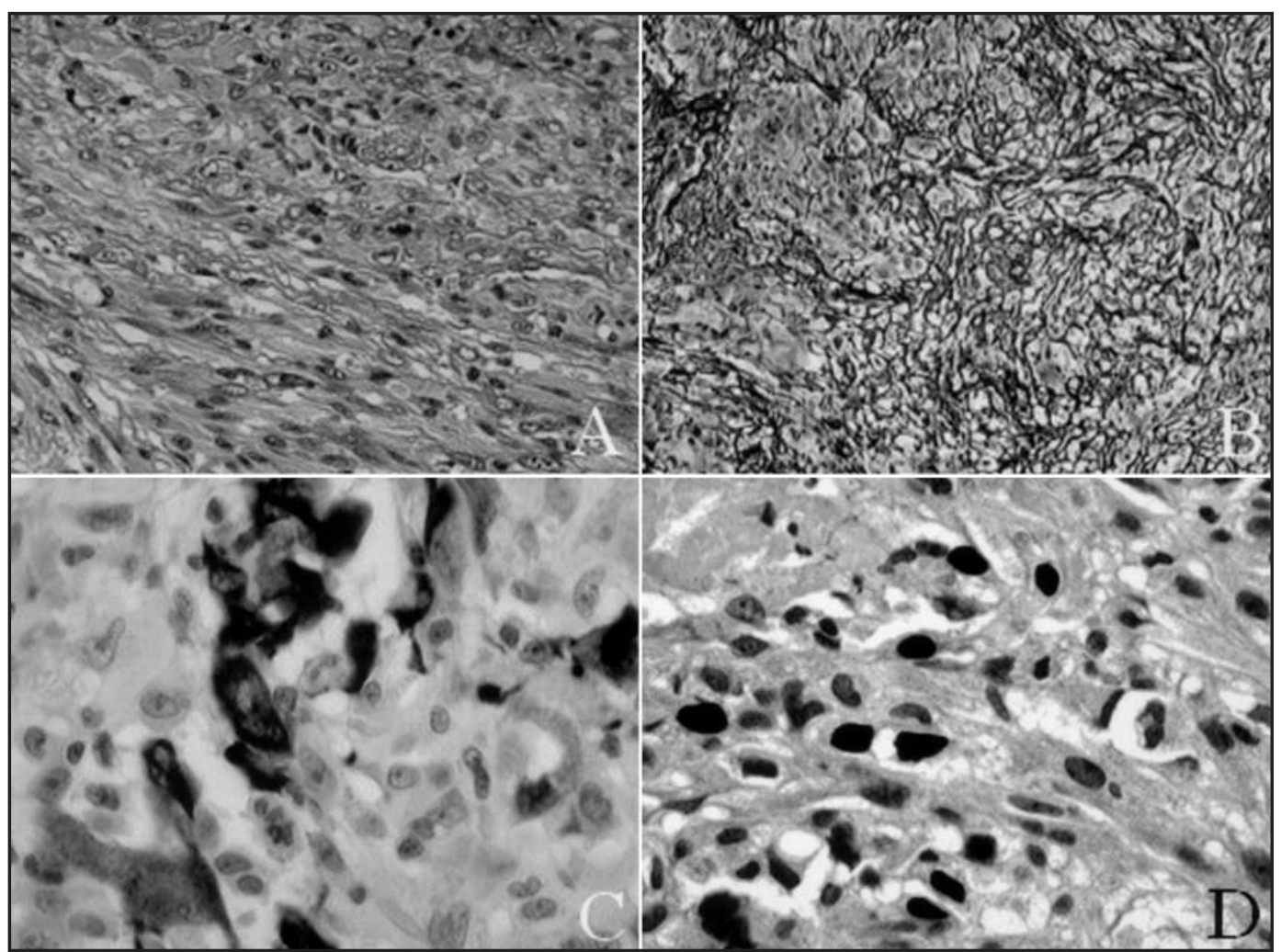

Fig 2. A, Photomicrography displaying the biphasic architecture of gliosarcoma (HE 200X); $B$, expression of reticulin fibers on histochemical preparation (100X); C, intracytoplasmic positivity for GFAP in glial cells (400X); $D$, intranuclear staining for p53 (400X).

Table 2. Immunohistochemical findings of gliosarcomas.

\begin{tabular}{|c|c|c|c|c|c|c|}
\hline Case & GFAP & Vimentin & CD34 & p53 & EGFR & Ki-67 \\
\hline \multirow[t]{2}{*}{1} & $G-D$ & $G-F$ & $G-N$ & G +++ & $G-N$ & G +++ \\
\hline & $S-N$ & $S-D$ & $S-N$ & S ++ & $S-N$ & $S+$ \\
\hline \multirow[t]{2}{*}{2} & $G-D$ & $G-F$ & $G-N$ & $G+++$ & $G-N$ & G + \\
\hline & $S-N$ & $S-D$ & $S-N$ & $\mathrm{~S}+++$ & $S-N$ & $S+$ \\
\hline \multirow[t]{2}{*}{3} & $G-D$ & $G-F$ & $\mathrm{G}-\mathrm{N}$ & G +++ & $G-N$ & G ++ \\
\hline & $S-N$ & $S-D$ & $\mathrm{~S}-\mathrm{N}$ & $\mathrm{S}+++$ & $S-N$ & $\mathrm{~S}++$ \\
\hline \multirow[t]{2}{*}{4} & $G-D$ & $G-F$ & $G-N$ & $\mathrm{G}+$ & $G-P$ & G ++ \\
\hline & $S-N$ & $S-D$ & $S-N$ & $S++$ & $S-N$ & $\mathrm{~S}++$ \\
\hline
\end{tabular}

G, glial component; S, sarcomatous component; D, diffuse positivity; F, focal positivity; N, negative; P, positive; + , staining of less than $1 \%$ of nuclei; ++ , staining of 1 to $5 \%$ of nuclei; +++ , staining of more than $5 \%$ of nuclei; GFAP, glial-fibrillary-acidic protein; EGFR, epidermal growth factor.

\section{DISCUSSION}

GSa is a rare morphological variant of glioblastoma, predominant in males, with age ranging from the fourth to the sixth decades, with a slight predilection for the temporal lobes ${ }^{1,3,4-6}$. In our present report, GSa accounted for $1.06 \%$ of all glioblastomas, with a mean age of 39 . However, the occurrence of a GSa in a 22-year old patient is uncommon. We failed to observe an anatomical site of predilec- tion. In spite of some reports of metastatic spread ${ }^{7}$, none of the patients reported herein evolved with systemic dissemination.

On clinical basis, primary glioblastomas and gliosarcomas are indistinguishable, both presenting with short clinical course, low median survival and similar peak of incidence ${ }^{1,3,6,8-11}$; hence the inclusion of GSa in the same clinical trials of glioblastomas ${ }^{3}$. The mean duration of symptoms in our patients 
(17 months) was somewhat longer due to a particular case presenting with symptoms for 48 months.

The treatment does not differ from that performed on glioblastomas, consisting of surgical resection and, depending on clinical status, radiotherapy and/or chemotherapy ${ }^{3,6}$. Patients who receive radiotherapy have a longer overall median survival (mean 10.6 months) when compared to patients submitted to surgery only (mean 6.2 months), according to Perry et al. ${ }^{6}$. However, one should notice that patients eligible for radiation therapy present with higher performance status, younger age and more favorable prognostic factors. In our series only two patients were eligible for adjuvant therapy and the mean overall survival was 4.5 months, a rate consistent with the marked positivity for proliferation index marker Ki-67 observed on immunohistochemical evaluation.

The histogenesis of GSa has been subject of debate. Feigin et al., who defined the sarcomatous component as a proliferation of glioblastoma blood vessels, first assessed it ${ }^{2}$. However, immunohistochemical studies have failed to detect endothelial markers in the sarcomatous component ${ }^{6,12,13}$. In the present study, only blood vessels stained positively for CD34.

The monoclonal theory was first proposed by Biernat et al., who demonstrated identical p53 mutations in both tumor areas ${ }^{14}$. Subsequently, Boerman et al., using comparative genomic hybridization, fluorescence in situ hybridization, cytogenetic analysis and microsatellite analysis, described genetic alterations shared by both tumor components ${ }^{15}$. Reis et al., assessing the genetic profile of 19 GSa patients, have found identical PTEN mutation, p53 nuclear accumulation, p16 deletion and CDK4 amplification in both tumor areas ${ }^{11}$. Recently, Actor et al. have reported that $57 \%$ off all chromosomal imbalances detected by comparative genomic hybridization of eight GSa were shared by both components. These authors have also detected identical p53 mutations in both glial and sarcomatous areas in 13 of 38 patients ${ }^{16}$. In our study, p53 nuclear accumulation was detected by immunohistochemistry in all 4 cases studied and the degree of staining was similar in glial and sarcomatous regions.

The frequency of $\mathrm{p} 53$ mutations observed in GSa is considered to be intermediate between primary and secondary glioblastomas, with the former presenting approximately $11 \%$ and the latter, $67 \%{ }^{17}$. We attribute the finding of p53 positivity in both components in all of our cases to the considerably small cohort. However, its role in the tumorigenesis of GSa cannot be ruled out.

Actor et al. have described EGFR overexpression in $8 \%$ of 38 tumors, with staining of both components in only one case ${ }^{16}$. Previous studies have reported EGFR overexpression and amplification as absent ${ }^{11}$. In our study, we detected EGFR immunostaining in only one case, which showed positivity in the glial area and negativity in the sarcomatous one.

In conclusion, GSa in our series present clinical and some genetic features similar to primary glioblastomas. An extremely low rate of EGFR overexpression remains as the most striking difference between these two entities. Furthermore, the TP53 tumor-supressor gene mutation seems to play a pathogenetic role in GSa and the authors believe there is strong evidence concerning its monoclonal origin. However, different molecular and genetic events may participate in the pathogenesis of GSa and deserve further investigation.

\section{REFERENCES}

1. Ohgaki H, Biernat W, Reis R, Hegi M, Kleihues P. Gliosarcoma. In Kleihues P, Cavenee WK (eds). Pathology and genetics of tumors of the nervous system. Lyon: IARC Press 2000:42-44.

2. Feigin IM, Allen LB, Lipkin L,Gross SW. The endothelial hyperplasia of the cerebral blood vessels and its sarcomatous transformation. Cancer 1958;11:264-277.

3. Meis JM, Martz KL, Nelson JS. Mixed glioblastoma multiforme and sarcoma: a clinicopathologic study of 26 Radiation Therapy Oncology Group cases. Cancer 1991;67:2342-2349.

4. Jack CR Jr, Bhansali DT, Chason JL, et al. Angiographic features of gliosarcoma. AJNR 1987;8:117-122.

5. Morantz RA, Feigin I, Ransohoff J III. Clinical and pathological study of 24 cases of gliosarcoma. J Neurosurg 1976;45:398-408.

6. Perry JR, Ang LC, Bilbao JM, Muller PJ. Clinicopathologic features of primary and postradiation cerebral gliosarcoma. Cancer 1995;75:2910-2918.

7. Witwer BP, Salamat MS, Resnick DK. Gliosarcoma metastatic to the cervical spinal cord: case report and review of the literature. Surg Neurol 2000;54:373-379.

8. Burger PC, Scheithauer BW. Gliosarcoma. In Burger PC, Scheithauer BW (eds). Tumors of the central nervous system. Washington DC: Armed Forces Institute of Pathology, 1994:68-70.

9. Kaschten B, Flandroy P, Reznik M, Hainaut H, Stevenaert A. Radiationinduced gliosarcoma: case report and review of the literature. J Neurosurg 1995;83:154-162.

10. Lutterbach J, Guttenberger R, Pagenstecher A. Gliosarcoma: a clinical study. Radiotherapy Oncol 2001;61:57-64.

11. Reis RM, Konu-Lebleblicioglu D, Lopes JM, Kleihues P, Ohgaki H. Genetic profile of gliosarcomas. Am J Pathol 2000;156:425-432.

12. Grant JW, Steart PV, Aguzzi A, Jones DB, Gallagher PJ. Gliosarcoma: an immunohistochemical study. Acta Neuropathol 1989;79:305-309.

13. Sreenan JJ, Prayson RA. Gliosarcoma: a study of 13 tumors, including p53 and CD34 immunohistochemistry. Arch Pathol Lab Med 1997; 121:129-133.

14. Biernat W, Aguzzi A, Sure U, Grant JW, Kleihues P, Hegi ME. Identical mutations of the p53 tumor supressor gene in the gliomatous and the sarcomatous components suggests a common origin from glial cells. J Neuropathol Exp Neurol 1995;54:651-656.

15. Boerman RH, Anderl K, Herath J, et al. The glial and mesenchymal elements of gliosarcomas share similar genetic alterations. J Neuropathol Exp Neurol 1996;55:973-981.

16. Actor B, Cobbers JMJL, Buschges R, et al. Comprehensive analysis of genomic alterations in gliosarcoma and its two tissue components. Genes Chromosomes Cancer 2002;34:416-427.

17. Watanabe K, Tachibana O, Sato K, Yonekawa Y, Kleihues P. Ohgaki H. Overexpression of EGF receptor and p53 mutations are mutually exclusive in the evolution of primary and secondary glioblastomas. Brain Pathol 1996;6:217-224. 